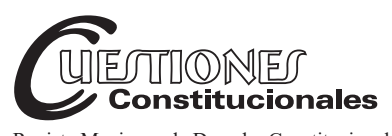

Revista Mexicana de Derecho Constitucional Núm. 39, julio-diciembre 2018

\title{
El principio constitucional de justicia e igualdad real y la acción afirmativa
}

\section{The Constitutional Principle of Justice and Real Equality and Affirmative Action}

\section{Víctor Granados BozA*}

\begin{abstract}
RESUMEN: El principio constitucional de justicia e igualdad real en los Estados constitucionales de derechos, plantea la controversia de su aplicación en contextos en donde las condiciones son de desigualdad y discriminación estructural, para ello es necesario que desde el ordenamiento jurídico se creen alternativas que garanticen la igualdad sustancial y el derecho a la diferencia. Para ello, en la Constitución del Ecuador de 2008 se integran figuras como la acción afirmativa, la política de restitución y la compensación a las brechas e injusticias sociales; sin embargo, es necesario analizar si sus resultados alcanzan los objetivos previstos o se reducen a tratos diferenciales de grupos sociales tradicionalmente excluidos.
\end{abstract}

Palabras clave: discriminación, igualdad, justicia, exclusión, acción positiva, acción afirmativa.
ABSTRACT: The constitutional principle of justice and real equality in the Constitutional States of Rights, raises the controversy of its application in contexts where the conditions are of inequality and structural discrimination, for it is necessary that the legal system creates alternatives that guarantee substantive equality $l$ and the right to diversity. For this, the Constitution of Ecuador 2008 integrates figures such as affirmative action, policy of restitution and compensation to gaps and social injustices, however it is necessary to analyze whether their results achieve the intended objectives or are reduced to differential treatment of social groups traditionally excluded.

Keywords: New Constitucionalism, Fundamental Right, Interpretation, Affirmative Action.

* Director del Instituto Superior de Posgrado en Ciencias Internacionales "Dr. Antonio Parra Velasco", de la Universidad de Guayaquil. Actualmente cursa el doctorado en Ciencias Jurídicas en la Universidad de La Habana.granadosboza@gmail.com. 
Sumario: I. Hacia una definición del problema conceptual y práctico de la acción afirmativa. II. Estado constitucional de derecho y acción afirmativa. III. De la justicia contractualista a los postulados de justicia social. IV. Justicia social y modelos constitucionales del Estado de derecho. V. Acción afirmativa en el marco de la discriminación estructural. VI. Medidas de acción afirmativa como reparación a la desigualdad $y$ discriminación. VII. Criterios a ser considerados en la aplicación de medidas restitutivas y compensatorias. VIII. Conclusiones. IX. Bibliografía.

\section{HACIA UNA DEFINICIÓN DEL PROBLEMA CONCEPTUAL Y PRÁCTICO DE LA ACCIÓN AFIRMATIVA}

La concepción de justicia e igualdad real en que se inscriben las acciones afirmativas nos remite a uno de los debates conceptuales en materia de la teoría garantista; paradigma dentro del cual se producen las transformaciones fundamentales del Estado constitucional de derecho que impulsan gobiernos latinoamericanos, ante escenarios económicos y sociales cambiantes, como perspectiva radical del nuevo diseño de la institucionalidad política, llevada a cabo como estrategia liberadora y de transición para resolver los efectos causados por políticas neoliberales implementadas desde gobiernos conservadores que mantuvieron y profundizaron niveles de desigualdad e inequidad en grupos sociales de bajos ingresos, especialmente aquellos que han sido tradicionalmente excluidos: indígenas, afrodescendientes, discapacitados, portadores de VIH, así como por diferencias culturales, condición socioeconómica, orientación sexual e ideología.

El esquema constitucional de 2008 en el Ecuador está orientado al reconocimiento, goce y ejercicio de los derechos fundamentales a través de la constitucionalización de los derechos por la fuerza vinculante de la Constitución, lo cual ha incidido en la evolución de las normativas jurisprudenciales y doctrinales en materia constitucional, transformando la organización jurídica y política del Estado, a través de la directa aplicación de la nueva dogmática constitucional, a efectos de responder y resolver las demandas ciudadanas y conflictos jurídicos con la efectiva tutela de los derechos. 
Este enfoque exige profundizar en la esencia y matriz conceptual de la acción afirmativa, proveniente de modelos capitalistas y democracias representativas que orientan dichas medidas hacia la retribución social para mitigar en algo el impacto nocivo del sistema, cuyo enfoque exclusivamente de acceso a cuotas, basados en gratificaciones y políticas de compensación tienen una clara tendencia hacia la reproducción de la discriminación y exclusión estructural, cuyas consecuencias en materia de educación superior es la perpetuación de la jerarquización y estratificación social, esto es la desigualdad e inequidad para grupos minoritarios que pertenecen a las mayorías que configuran los sectores tradicional e históricamente excluidos.

La problemática del garantismo de los derechos constitucionales en la educación superior ecuatoriana, se ahonda cuando las políticas públicas y el ordenamiento jurídico expresan la orientación y responsabilidad del Estado de plantear un sistema de acceso orientado hacia la expansión de una democracia deliberativa basada en un proceso de constitucionalización social, que exige acciones de resistencia a la mercantilización a la vez que la recuperación y resignificación del sentido de lo público en favor del bien común y el interés general, en el marco de la sociedad del Buen Vivir (Sumak Kawsay).

Esto obligó a generar políticas en el Ecuador a través de un sistema de acciones positivas con énfasis en la gratuidad de la educación superior, universalizando la formación del tercer nivel, así como la elaboración de un proceso de acceso a través del Examen Nacional de Educación Superior (ENES), centrado en la medición de aptitudes y capacidades de razonamiento y no de conocimientos.

El planteamiento de la política de cuotas, la exigibilidad en las universidades públicas de mecanismos de nivelación para reducir brechas cognitivas, el fortalecimiento de las instituciones de educación superior públicas para el mejoramiento de su calidad académica, a través de nuevas fórmulas de distribución de recursos, la integralidad del sistema educativo como responsabilidad del Estado, entre otras.

En su versión inicial, el sistema de admisión acrecentó el acceso a la educación superior, ${ }^{1}$ duplicando entre 2006 y 2014, del 33 al 66\% la pro-

1 Según el Instituto Nacional de Estadística y Censos del Ecuador, entre 2000 y 2010 se acrecentó la tasa de matrícula en educación superior en $12.4 \%$, cuatro puntos más que en la década anterior y 10 con relación a la década de los ochenta del siglo pasado. 
babilidad de acceso del $20 \%$ de la población más pobre; superando en $1.8 \%$ la tasa de crecimiento poblacional; reduciendo del 45 al $25.9 \%$ el porcentaje de jóvenes entre los 18 y 24 años que no accedía al tercer nivel educativo por razones económicas, debido a que desde 2013 el 67\% de la matrícula se concentraba en la universidad pública. Un dato relevante es que el $73 \%$ de los estudiantes que rindieron el examen ENES para el ingreso a la educación superior, son los primeros de su familia en acceder a este nivel de estudios, siendo cuatro veces más alta la probabilidad de constituirse en la primera generación que accede a la universidad entre 2006 y $2014 .^{2}$

Sin embargo, a pesar de estos logros con relación a los efectos garantistas de la exigibilidad del derecho a la educación superior, la realidad demuestra que la problemática se centra en que si se pretende alcanzar un desarrollo humano integral superador de contextos y secuelas de la discriminación, no es recomendable que las políticas de acción afirmativa se concentren exclusivamente en el ingreso de los sectores tradicionalmente excluidos, puesto que en sociedades como la ecuatoriana en proceso de construcción de democracias más humanas y sostenibles, es necesario plantearse otros criterios que amplíen la base conceptual del acceso-consumo, avanzando hacia el aseguramiento de la igualdad de oportunidades en el tránsito y la titulación, configurando interacciones socioculturales incluyentes.

Situaciones como la reducción de cupos debido a la débil pertinencia en la planificación de las instituciones de educación superior públicas, ${ }^{3}$ la concentración del $30 \%$ de la población más rica en las universidades privadas generando "circuitos socialmente diferenciados", ${ }_{4}^{4}$ que se expresan en las altas tasas de titulación de dichos sectores sociales en desmedro de los más pobres, permiten deducir que las acciones afirmativas deben definirse como medidas que contengan y expresen objetivos relacionados con la distribución social del conocimiento, que realmente superen la "selección implícita"5 y excluyente que se opera en el sistema de educación

2 Secretaría Nacional de Educación Superior, Ciencia, Tecnología e Innovación, Logros y avances del sistema de educación superior ecuatoriano, Quito, Senescyt, 2014.

3 Diecisiete mil cupos en la universidad pública en 2015 a pesar de su capacidad instalada.

4 Ramírez, René, Universidad urgente para una sociedad emancipada, Ecuador, Senescyt-IESALC, 2016, p. 22

5 Duarte, Bernardo, "El acceso a la educación superior: sistemas de admisión a las 
superior, que se produce a lo largo del proceso de formación universitaria, profundizándose en los primeros años debido a la deserción y reduciéndose en el ingreso al posgrado.

En este sentido, un sistema constitucional garantista de derechos debe concebir la acción afirmativa como una medida de carácter redistributivo en el acceso, permanencia, tránsito y egreso de la educación superior de sectores tradicionalmente excluidos, que supere las brechas cognitivas existentes que son consecuencia de estructuras y condiciones de desigualdad que inciden negativamente en su desempeño educativo, a partir de la generación de contextos y políticas restitutivas integrales.

La acción afirmativa debe destinarse al fortalecimiento del capital cultural y social de los sectores excluidos con miras a lograr su movilidad social ascendente, si se pretende asegurar no sólo el consumo del conocimiento, sino también el futuro de la nuevas generaciones y de las democracias humanas ${ }^{6}$ deliberativas, donde la responsabilidad del Estado como el de la sociedad civil son fundamentales para la ampliación de oportunidades, que hagan posible en el corto y mediano plazo, que el nuevo talento humano de la nación tenga competencias educativas que posibiliten su participación en la construcción de alternativas del saber orientadas a la reducción de la pobreza y de las asimetrías sociales.

Se propone entonces el paso de una definición de las medidas de acción afirmativa de carácter retributivas, compensatorias y temporales, a una conceptualización que se inserte en el sentido de lo público y de lo procomún del conocimiento y del aprendizaje como derechos humanos universales, esto es, que sean redistributivas, de restitución integral de derechos y sostenibles en el tiempo para la superación de la discriminación estructural.

universidades nacionales de Argentina", ponencia presentada en el Primer Congreso Nacional de Estudios Comparados en Educación, Buenos Aires, 2005.

6 Si bien es cierto como sostienen Przeworsky (Democracy and Development, KIT Publishers, 2000) y Sen (La idea de la justicia, México, Taurus, 2010) las democracias son la única forma de libertad política factible que hacen posible la toma de decisiones y oportunidades reales dadas las circunstancias personales y sociales específicas de los ciudadanos, también han sido sistemas que conviven con situaciones estructurales de desigualdad que se alejan del bienestar y de la convivencia armónica en los ámbitos sociales, políticos y ambientales, que no promueven la dignidad y la condición humana, por lo que algunas democracias representativas son profundamente inhumanas y excluyentes. 
Cabe cuestionarse alrededor de la aplicación de las medidas de acción afirmativa en el sistema de educación superior ecuatoriano, sobre todo en lo relacionado a: ¿cuáles son los mecanismos de control legal para el cumplimiento de las acciones afirmativas, que garanticen el derecho constitucional a la igualdad de oportunidades en las universidades?

¿De qué manera se podrá eliminar la producción de los circuitos diferenciadores que intervienen en la distribución de la matrícula y en las condiciones de tránsito y egreso de personas y grupos sociales tradicionalmente excluidos para evitar en el Ecuador las "inclusiones desiguales y discriminatorias"??

Por tanto, es menester plantearse como hipótesis de la investigación la urgencia de que las entidades rectoras de la educación superior diseñen un sistema normativo y procesal que asegure idóneos mecanismos de orden legal, administrativos y fácticos para la exigibilidad y control reglamentario en la aplicación e instrumentación de la acción afirmativa, que garantice en la realidad y de manera integral la adecuada observancia y aplicación del principio de igualdad de oportunidades en las instituciones de educación superior.

\section{ESTADO CONSTITUCIONAL DE DERECHO Y ACCIÓN AFIRMATIVA}

Sin duda, la temática se inserta en el debate actual del constitucionalismo y neoconstitucionalismo, de contrapoderes y reglas, así como de la importancia que cumplen en el rol normativo de las garantías a los derechos fundamentales, al que se anticiparon Comanducci ${ }^{8}$ y Guastini ${ }^{9}$ en la tesis sobre las "Formas de (neo)constitucionalismo" y la teoría de las "condiciones de constitucionalización". ${ }^{10}$

7 Sen, Amartya, La idea de la justicia, México, Taurus, 2010, p. 45.

8 Comanducci, Paolo, "Formas de (neo)constitucionalismo", Isonomía, México, Instituto Tecnológico Autónomo de México, núm. 16, 2002.

9 Guastini, Riccardo, La “constitucionalización” del ordenamiento jurídico: el caso italiano, Madrid, Trotta, 2005.

10 San Miguel, Johannes y Granados, Víctor, “¡Del romanticismo al realismo mágico! Contenido y principales postulados de la tesis neoconstitucional europea y latinoamericana", Cadernos de Dereito Actual, núm. 4, 2016, disponible en: http://www.cadernosdedereitoactual.es/ojs/index.php/cadernos/article/view/95. 
De ahí también el interés por superar la formalidad retórica para avanzar hacia la eficacia jurídica en la protección de los derechos subjetivos, a través de complejas soluciones normativas que empoderen el sentido común hacia una mayor participación de la ciudadanía en la construcción social de una mejor calidad de vida, fortalecimiento de democracias inclusivas y la civilidad política.

El interés por alcanzar sociedades menos discriminatorias han sido detonantes en las luchas sociales a lo largo de la historia, como las desplegadas por líderes y actores de los movimientos sociales estadounidenses alrededor de los derechos civiles, inspirados en los principios de libertad, igualdad y fraternidad, proclamados en la Declaración de Derechos de Virginia (1776), y en la Revolución Francesa (1789).

Las medidas de acción afirmativa tienen su origen en los Estados Unidos de América, con motivo de las jornadas de lucha de los movimientos sociales que a mediados del siglo XX se opusieron a seguir soportando la carga de la discriminación que pesaba sobre ellos. En tal sentido, se trata de una institución exigida por las organizaciones civiles estadounidenses, que luego fue extendiéndose a diferentes países hasta convertirse en una opción característica de los sistemas democráticos de gobierno; y, más recientemente, en una política de Estado incorporada a diferentes textos constitucionales.

Tanto el nombre como el contenido inicial de dicha institución pertenecen al léxico del idioma inglés; así, en su Dictionary of Law, P. H. Collin consigna que: "affirmative action: noun US a policy of positive discrimination to help groups in society who have a disadvantage (NOTE: The British equivalentes equal opportunity)" ${ }_{11}^{11}$ mientras que en su Diccionario bilingüe de terminología jurídica, Francisco R. Bossini y Mary Gleeson definen la expresión "affirmative action" como "normas que se dan para evitar conductas o situaciones discriminatorias, utilizadas especialmente contra ciertos patronos que se aprovechan, infravalorando económicamente el trabajo de grupos minoritarios". ${ }^{2}$

La expresión "affirmative action", traducida literalmente del inglés al español, es "acción afirmativa", razón por la cual es el nombre con que se conoce una institución jurídica, a la que suele hacerse referencia también

11 Collin, P. H., Dictionary of Law, Bloomsbury Publishing Plc, 2004, p. 10.

12 Bossini, Francisco R. y Gleeson, Mary, Diccionario bilingüe de terminología jurídica, Madrid, McGraw-Hill, 1998, p. 15. 
con otros nombres como "discriminación inversa", "discriminación positiva" o "acciones positivas", sin que en todos los casos las expresiones sean equivalentes.

Según Barrere, la acción afirmativa que surge como una normativa laboral estadounidense emitida en 1935, adquiere el estatus de política como respuestas jurídicas a los movimientos sociales afroamericanos y de otras minorías adoptando las condiciones necesarias que hicieran surgir el derecho antidiscriminatorio, cuya esencia de representación resulta ser medular. $^{13}$

Dichos conceptos de corte empresarial fueron transferidos a la educación superior en 1978 con el caso Bakke, ${ }^{14}$ bajo la argumentación de que las universidades debían de generar políticas compensatorias de admisión de grupos minoritarios porque han sido tradicional e históricamente excluidos de su participación en la formación terciaria y por la necesidad institucional de tener acercamientos con las comunidades más empobrecidas de la sociedad.

Las llamadas por Juan Williams Kudín"15 "barreras" de participación para analizar la política de acción afirmativa del presidente Nixon en la década de los setenta del siglo pasado, conduce al análisis jurídico de las medidas compensatorias destinadas a aquellos grupos minoritarios que son tradicionalmente excluidos y al desarrollo de políticas de restitución de derechos de poblaciones pobres y discriminadas, en términos de generar oportunidades para su desarrollo con miras a reducir las inequidades sociales.

13 Barrere, María de los Ángeles, "Discriminación, derecho antidiscriminatorio y acción positiva versus Igualdad de oportunidades", Revista Vasca de Administración Pública, núm. 60, 2001, p. 149.

14 El caso Bakke vs. Universidad de California, se produce por políticas de acción afirmativa que la Facultad de Medicina adoptó en favor de grupos étnicos minoritarios, estableciendo 16 cupos para la admisión. Sin embargo, algunos de los promedios de los aspirantes de ascendencia caucásica eran superiores a los de los grupos minoritarios que fueron admitidos gracias a que los requisitos de ingresos eran de menor exigencia, ya que se basaban prioritariamente en el color de la piel y en su pertenencia a sectores étnicos.

15 Williams, Juan, "En pos de una defensa proactiva de la acción afirmativa: derribando mitos y reformulando el debate", en Díaz Romero, Pamela et al., Caminos para la inclusión en la educación superior, Perú, Fundación Equitas-Organización de Estados Iberoamericanos, 2006, pp. 41-59. 
En este contexto, autores como Greenwalt, quien aporta el concepto de "discriminación inversa", ${ }^{16}$ y Fullinwider, con la propuesta del "trato preferencial", ${ }^{17}$ se enmarcan en la llamada justicia distributiva, compensatoria y procesal-constitucional. ${ }^{18}$

Sobre "discriminación inversa", escribió Alfonso Ruiz Miguel, a propósito del llamado caso Kalanke, ${ }^{19}$ según dicho autor,

La discriminación inversa, al parecer, nació en la India, ya en los años treinta [siglo XX] como una política aceptada por los colonizadores británicos para intentar superar la aguda división de castas de aquella sociedad... sea como sea, lo cierto es que la pretensión de las políticas de discriminación inversa es intentar paliar situaciones de desigualdad particularmente recalcitrantes... ${ }^{20}$

La discriminación inversa, sería, en la opinión de Ruiz Miguel, lo opuesto a la discriminación clásica "que procede y se explica por siglos de opresión y desigualdad en contra de determinados grupos sociales concretos, pero que han adquirido un significado abstracto..."; mientras que la discriminación inversa, a diferencia de aquélla,

no contiene en absoluto ninguna motivación social despectiva o minusvaloradora, ni que se pueda asimilar a ella, ni siquiera de lejos... en segundo, lugar la finalidad de la discriminación inversa es, y debe ser, efectivamente, conseguir una situación social más igualitaria entre grupos injustamente discriminados con anterioridad. ${ }^{21}$

16 Greenwalt, Kent, La discriminación inversa, Nueva York, Alfred A. Knopf, 1983, p. 17.

17 Fullinwider, Robert, La controversia de la discriminación inversa, Nueva Jersey, Rowman y Littlefield, 1980, p. 101.

18 Esta tendencia ha generado profundas controversias en juristas estadounidenses, quienes argumentaron en su momento que las ventajas comparativas situadas en los grupos tradicionalmente excluidos generaban niveles de discriminación a las clases sociales pudientes, sobre todo en el caso del acceso al trabajo y a la educación.

19 El caso c/450/93 del 17 de octubre de 1995, que contiene la sentencia del Tribunal de Justicia de las Comunidades Europeas sobre un ingeniero que competía con la ingeniera Glissmann por la Jefatura de Sección del Servicio de Parques y Jardines de la ciudad de Bremen, Alemania.

20 Ruiz, Alfonso, "La discriminación inversa y el caso Kalanke", Doxa, Cuadernos de Filosofía del Derecho, España, Universidad de Alicante, núm. 19, 1996, pp. 123-140.

21 Ibidem, pp. 130 y 131. 
La "discriminación positiva" constituye el núcleo analítico de la ponencia presentada por José Asti Heredia, Bruno Nazario Sánchez y Katia Iparraguirre Alarcón, en la XVIII Conferencia Anual de la Asociación Latinoamericana y del Caribe de Derecho y Economía en 2014; para los autores,

La discriminación positiva o inversa... es una forma o instrumento de acción positiva especialmente incisivo, y consiste en una medida diferenciadora encaminada a privilegiar a quienes pertenecen a un grupo desfavorecido, es decir, aquellos grupos que han sufrido una situación de discriminación adversa. ${ }^{22}$

Estas posturas introducen el concepto de la acción afirmativa en la esfera de la reparación social que, según Tierney ${ }^{23}$ y otros autores, está guiada por los principios de compensación, corrección y diversificación.

La compensación relacionada con el daño producido a grupos minoritarios por determinados sectores; la corrección como política destinada a rectificar jurídica y socialmente las inconsistencias o desviaciones del sistema, y la diversificación como mecanismo de reconocimiento de las experiencias de individuos o grupos minoritarios como "fuerza del futuro".

A partir de estos criterios se concibe a la acción afirmativa como un instrumento político que posibilita el combate contra la discriminación, es decir, que se implica con la pretensión de reducir las asimetrías sociales mediante el ejercicio pleno e igualitario de los derechos fundamentales.

Cohen y Sterba, proponen la necesidad jurídica y social de fundamentar la acción afirmativa en el aseguramiento de una serie de beneficios que para el caso de la educación superior, están destinados a favorecer a "un cuerpo estudiantil racial y étnicamente diverso", sobre todo de aquellos que han sido históricamente discriminados, ya que la discriminación exige respuestas inmediatas articuladas a la igualdad de oportunidades. ${ }^{24}$

22 Asti, José et al., "Discriminación positiva: un acercamiento sobre la inclusión de la mujer en la política peruana a propósito de las cuotas de género", s. p. i., 2014, p. 14.

23 Tierney, William, "The Parament of Affirmative Action: Equity and Excellent in the Academy", Review of Educational Research Summer, vol. 67, núm. 2, 1997, pp 165196.

24 Cohen, Carl y Sterba, James, Affirmative Action and Racial Preferences: A Debate, Nueva York, Oxford University Press, 2003, p. 205. 
La "retórica sobre el tratamiento preferencial o la discriminación inversa" según Williams, ${ }^{25}$ no puede reducirse a medidas simplistas como las políticas de cuotas orientadas a efectivizar medidas de acción afirmativas, pero muchas veces emitidas sin definiciones ni criterios claros de los perfiles y parámetros relacionados con la selección, porque los requisitos de elegibilidad están relacionados con los contextos y condiciones socioculturales de origen de los grupos discriminados.

La acción afirmativa expresada en política de cuotas, en ciertos casos profundiza los niveles de exclusión en términos de futuro, violando el sistema garantista de derechos, ya que el acceso a la educación superior no asegura el tránsito y el egreso en condiciones de calidad, ni la meritocracia es un principio que responde de forma pertinente a la escasa idoneidad de competencias de los grupos tradicionalmente excluidos, ya que existe una relación directamente proporcional entre la pobreza y las brechas cognitivas.

Cohen y Sterba ${ }^{26}$ plantean que las críticas relacionadas con el argumento de que el trato preferencial a individuos y grupos tradicionalmente excluidos, merma los derechos a individuos que no han sido objeto de discriminación, no pueden sostenerse, presentando dos tesis al respecto: a) la primera consiste en el concepto de discriminación estructural que han sufrido los grupos minoritarios que ameritan medidas compensatorias, entre ellas, la prioridad de selección debido a que los otros segmentos de la población se han beneficiado de dichas formas discriminatorias, aunque no hayan sido responsables directos de las mismas, y b) la segunda que sostiene que el devenir histórico de grupos no excluidos constituye en educación verdaderos legados, que en algunos países como Estados Unidos de América significan hasta el $25 \%$ de los estudiantes que ingresan a universidades selectas.

En Ecuador, en condiciones casi similares de conflictividad social, mercantilización e inequidades, ha experimentado la influencia de corrientes neoconstitucionalistas, bajo cuyo prisma se adoptan políticas públicas de tutela, protección de derechos y libertades como núcleo potenciador del buen vivir.

De este modo, al momento de establecer el reconocimiento y compensación a los grupos sociales históricamente vulnerables y excluidos que, a

\footnotetext{
25 Williams, Juan, "En pos de una...", cit., p. 42.

26 Ibidem, p. 266.
} 
efectos de disminuir tales diferencias, el Estado constitucional de derecho y justicia, apunta a constitucionalizar una gama de derechos orientados a promover el disfrute de oportunidades, en condiciones de igualdad, calidad, pertinencia y garantías.

Para dichos fines, la Constitución de la República del Ecuador, en el título acerca de los derechos establece: "El Estado adoptará medidas de acción afirmativa que promuevan la igualdad real en favor de los titulares de derechos que se encuentren en situación de desigualdad". ${ }^{27}$

En tal sentido, la concepción de justicia e igualdad real se sustenta en principios y doctrinas pro ser humano, y en los nuevos paradigmas jurídicos que legitiman la fuerza normativa de la Constitución, su inmediata aplicación, eficacia directa y no restricción de derechos, en favor de los ciudadanos que se encuentran en situación de desigualdad, que cuentan con opciones y recursos jurídicos idóneos en la variada gama de derechos y garantías establecidos al amparo de la normativa neoconstitucionalista.

Los cambios en el sistema político y jurídico introducidos por los asambleístas constituyentes de Montecristi, en la Constitución de 2008, establecen en su diversidad y expectativas ideológicas un nuevo sistema de fuentes y control de constitucionalidad, el principio de aplicación directa e inmediata de la norma constitucional que convierte a la justicia constitucional en factor de supremacía y contención en contra del abuso de la ley y del poder.

Por lo que conviene preguntarse si estos significativos cambios en el modelo político-jurídico, que marcan un antes y un después en el Ecuador, han contribuido realmente al advenimiento del Estado constitucional de derecho y justicia.

¿Significa entonces que el neoconstitucionalismo, su ideología y valores marcan una honda de largo alcance y transición que ha permitido entender y remediar en parte las crisis jurídicas, las tensiones políticas y sociales de los Estados que adoptaron el modelo neoliberal a fines del siglo pasado?

Así pues, se conoce que este periodo estuvo caracterizado por la volatilidad del sistema democrático, la corrupción, la impunidad, los abusos del poder y la violación sistemática de libertades y derechos fundamentales,

27 Constitución de la República del Ecuador, año II, R.O., núm. 449, Quito, 20 de octubre de 2008, artículo 11.2. 
entre ellos, el acceso a la educación y su impacto en los contextos y campos de aplicación.

En este proceso, la universidad como institución social tiene un papel relevante, orientado a la formación de una ciudadanía comprometida en la construcción de la sociedad del conocimiento, no sólo en la adquisición de saberes y competencias profesionales, sino inclusive en la generación de ciencia, tecnología, humanidades, en el marco de la defensa irrestricta de los derechos que aseguren el acceso, la gestión social y tecnológica del conocimiento, que contribuya al desarrollo del talento humano, las transformaciones sociales, económicas, culturales y su formación integral para la solución de los problemas del país.

\section{DE LA JUSTICIA CONTRACTUALISTA A LOS POSTULADOS}

DE JUSTICIA SOCIAL

La definición de justicia también estuvo presente en los planteamientos de Platón, en el libro La República y en su ideal de ciudad-Estado, donde sostiene que el enunciado de justicia está vinculado con la armonía social existente entre las diferentes partes de la sociedad, de tal forma que las leyes son consecuencia de las ideas y del criterio de lo justo y lo injusto, que deben ser practicados en la Polis, inherentes a sus funciones e interacciones, por lo que no podrán crearse normas contrarias a dichas leyes.

El vínculo de la justicia con la armonía social, es consustancial a la política y sus cuatro virtudes: prudencia, templanza, fortaleza y justicia, como elementos centrales de la teoría política clásica que implica la construcción de un enfoque distinto del ethos ciudadano, donde "la justicia es el bien humano por excelencia"; para concluir que la virtud suprema consiste precisamente en "dar a cada uno lo suyo". ${ }^{28}$

Para Aristóteles, la justicia consiste en "dar a cada uno lo que le corresponde; es decir, en proporción a su contribución con la sociedad, sus necesidades y méritos personales". ${ }^{29}$ Noción que por su amplitud ha generado algunas disquisiciones teóricas, con el propósito de establecer precisiones acerca de los fines de la vida en sociedad.

\footnotetext{
28 Platón, La República, Madrid, Institutos de Estudios Políticos, 1949, p. 434 c.

29 Aristóteles, Ética nicomaqua. Ética eudemia, Madrid, Gredos, 2003 pp. 21-23.
} 
Al retomar el planteamiento de Platón, Aristóteles establece el sentido y alcance del concepto de justicia distributiva que ha dejado huellas en definiciones de justicia social, en las que se enmarcan las múltiples dimensiones actuales del neoconstitucionalismo, que pretende distinguir qué aspectos, específicamente de la conflictividad humana, sus derechos y garantías y la influencia normativa del poder, corresponde al campo de la justicia constitucional.

Durante los siglos XVII al XIX, la corriente contractualista recibió la influencia de filósofos como Hobbes, ${ }^{30}$ Locke, ${ }^{31}$ Rousseau ${ }^{32}$ y Kant, ${ }^{33}$ pensadores considerados históricos, que han contribuido a la difusión del "contractualismo", saber que fundamentaron significativos cambios en la modernidad con el triunfo del progreso y los ideales de la razón, cuyo pensamiento sobre los fines de la sociedad, en líneas generales, se relaciona con la necesidad que experimentan los ciudadanos libres de establecer un ordenamiento en armonía social, desde las tendencias de la realidad social, cuanto del proceso de transformación del Estado sobre la base de una estructura de reglas e instituciones en que estriba el Contrato social, considerado referente en el marco institucional para la adecuada aplicación de la justicia, para el caso de tensiones entre intereses particulares, como consecuencia del Estado de naturaleza. ${ }^{34}$

De tal manera, si el Contrato social es el mecanismo que impulsa a la humanidad y la organiza, desde esta nueva perspectiva del pensamiento se podrá contribuir a los fines de la sociedad en el marco de relaciones políticas basadas en derechos y deberes, que no son inmutables y que pueden variar en función de construcciones sociales inclusivas, solidarias que contribuyan a reducir las brechas de la desigualdad y la pobreza existentes.

Las acepciones contemporáneas del concepto de justicia social hacen relación a tres postulados de carácter interdependientes y relacionados con

\footnotetext{
${ }^{30}$ Hobbes, Thomas, Leviatán, Oxford, Oxford Clasics, 1996.

31 Locke, John, Dos ensayos sobre el gobierno civil, México, Porrúa, 2003.

32 Rousseau, Jean Jacques, Contrato social, París, Gallimard Pléiade, 1964.

33 Kant, Inmanuel, Crítica de la razón pura, Madrid, Taurus, 2005.

34 Locke sostiene que el estado inicial de los seres humanos es de libertad, igualdad e independencia, por lo que es imprescindible el contrato social para que pueda desarrollarse el trabajo, la cultura, el transporte entre otros, que consiste en la adquisición de los derechos a cambio de renunciar a la libertad original que si se mantiene podría implicar riesgos permanentes de la vida.
} 
los procesos de discriminación que enfrentan los ciudadanos, en condiciones de exclusión, explotación y dominación; éstos son los siguientes:

- La distribución, referida a los bienes y recursos de índole material y cultural, siendo sus principales autores Rawls, ${ }^{35}$ Nussbaum $^{36}$ y Sen. ${ }^{37}$

- El reconocimiento, basado en el respeto a la diversidad de las culturas y de las personas, para el establecimiento de interacciones y relaciones sociales caracterizadas por la justicia, con sus principales exponentes, Fraser ${ }^{38}$ y Honnett. ${ }^{39}$

- La participación, como estrategia de aseguramiento de que los ciudadanos puedan acceder a la toma de decisiones que afecten su desarrollo, teniendo una dinámica activa en la sociedad, con miras a alcanzar su equilibrio social, así como el reconocimiento y empoderamiento del papel del sujeto y las actorías sociales.

\section{JUSTICIA SOCIAL Y MODELOS CONSTITUCIONALES DEL ESTADO DE DERECHO}

En el debate suscitado en Ecuador y América Latina acerca del Estado constitucional de derecho, la tutela y amparo de los derechos fundamentales, por medio de la centralidad de esos derechos constitucionales, nos remite al análisis del carácter polisémico del modelo neoconstitucionalista y su discurso argumentativo y paradigmático "frente a la atribución de fuerza vinculante de la jurisprudencia, sobre la cual subyace una ideología que irradia todas las instituciones públicas para resolver las tensiones que se presentan en la aplicación de los derechos fundamentales", como sostie-

35 Rawls, John, La justicia como equidad. Una reformulación, Madrid, Paidós Ibérica, 2001.

36 Nussbaum, Martha, Las fronteras de la justicia, Madrid, Paidós, 2007.

37 Sen, Amartya, La idea de la..., cit.

38 Fraser, Nancy, Unruly Practices: Power, Discourse and Gender in Contemporary Social Theory, Oxford, 1989.

39 Honneth, Alex, "Integrity and Disrespect: Principles of a Conception of Morality Based on the Theory of Recognition", Political Theory, vol. 20, núm. 2, mayo de 1992, pp. 188 y 189. 
nen Miguel Carbonell y Leonardo García Jaramillo, ${ }^{40}$ cuya fortaleza axiológica y orgánica en el Estado constitucional de derechos y justicia está dirigido al ejercicio de aquellas atribuciones y decisiones de los órganos y ramas del poder público, previstos constitucionalmente para garantizar la eficacia y garantías de los derechos fundamentales por medio de la aplicación directa de sus contenidos esenciales.

En este sentido, los derechos se convierten en atribuciones constitucionales, en cuanto conjunto de normas sustanciales de obligatorio cumplimiento, produciéndose — según Guastini——41 en una conjunción de carácter vinculante en el proceso de constitucionalización de los derechos.

Otros abordajes en el ámbito ideológico tienen que ver con Alexy, ${ }^{42} \mathrm{Za}$ grebelsky ${ }^{43}$ y Dworkin, ${ }^{44}$ que ratifican la necesidad de la ampliación de la razón de ser del texto constitucional alrededor de la eficacia en la garantía de los derechos fundamentales, incluso más allá de las limitaciones que pueda generar el poder del Estado.

Debemos coincidir en la significación compleja y más limitada para proteger los derechos frente a mecanismos procesales o actos originados en el Estado que, al usar la terminología de la preeminencia de los instrumentos de protección y tutela de los derechos fundamentales al plantearse como premisa básica la integración del derecho y la moral, se fortalece el iusnaturalismo, enfoque de la filosofía del derecho que había sido superado. ${ }^{45}$ Este debate sostiene la evidente debilidad de las interpretaciones judiciales para la definición y amparo de un derecho fundamental.

40 Carbonell, Miguel y García, Leonardo B., El canon neoconstitucional, Colombia, Universidad Externado, 2010.

41 Guastini, Riccardo, La “constitucionalización...", cit.

42 Alexy, Robert, Tres escritos sobre los derechos fundamentales y la teoría de los principios, Bogotá, Universidad Externado de Colombia, 2003.

43 Zagrebelsky, Gustavo, El derecho dúctil, Madrid, Trotta, 1997.

44 Dworkin, Ronald, A Matter of Principle, Oxford, Clarendon Press, 1986.

45 El iuspositivismo teórico tradicional y el paradigma formal de la interpretación normativa se derivan del formalismo jurídico, tanto en sus vertientes de la escuela exegética francesa de Portalis y Demolombe, la jurisprudencia de conceptos alemana o el normativismo de Kelsen y la escuela de Viena. Algunas de las tesis relevantes para el tema objeto de estudio las encontramos bajo análisis en Bobbio, Norberto, Teoría general del derecho, Madrid, Debate, 1991; Vecchio, Giorgio del, Los principios generales del derecho, Barcelona, Bosch, 1971; Ferrajoli, Luigi, "La teoría del derecho en el sistema de saberes jurídicos", en Ferrajoli, Luigi et al., La teoría del derecho en el paradigma cons- 
El argumento de mayor peso es el de Ferrajoli, ${ }^{46}$ al proponer que los derechos fundamentales están directamente relacionados por los niveles de pertenencia del titular de derechos a un determinado grupo o clase de persona, esto es género, mujer, minoría étnica.

Después de una aproximación básica acerca de la nueva realidad jurídica constitucional, es necesario establecer la importancia del catálogo de los derechos fundamentales, que resultan ser de especial interés, toda vez que incorporan principios para la comprensión e interpretación de la acción afirmativa, como el de dignidad, inclusión, estatus, seguridad jurídica, equidad, solidaridad e igualdad extensiva.

La definición de Ferrajoli plantea que son "derechos fundamentales" aquellos derechos subjetivos que corresponden universalmente a "todos" los seres humanos en cuanto dotados del estatus de personas o ciudadanos con capacidad de obrar; entendiéndolos como cualquier expectativa positiva (de prestaciones) o negativa (de no sufrir lesiones) adscrita a un sujeto por una norma jurídica; y por estatus la condición de un sujeto, prevista asimismo por una norma jurídica positiva, como presupuesto de su idoneidad para ser titular de situaciones jurídicas y/o autor de los actos que son ejercicio de éstas. ${ }^{47}$

En este sentido, se comprende que la extensión y calidad de los principios de supremacía constitucional y el de igualdad de oportunidades en la aplicación directa e inmediata de la norma constitucional para la protección de los derechos fundamentales dependerá del grado de democratización del ordenamiento jurídico, en cuanto a su intención de reducción de las diferencias de estatus que existen entre las diversas clases de sujetos que conviven en una determinada sociedad.

Para Luigi Ferrajoli, las condiciones que definen la igualdad y la desigualdad de los sujetos tienen que ver con la "personalidad" (identidad personal), la "ciudadanía" (identidad ciudadana) y la capacidad de obrar que históricamente han sido objeto de exclusiones, discriminaciones y limitaciones, constatando con preocupación que en la actualidad la exten-

titucional, Madrid, Fundación Coloquio Jurídico Europeo, 2008; Prieto Sanchís, Luis, Constitucionalismo y positivismo, México, Fontamara, 1997.

46 Ferrajoli, Luigi, "La teoría del derecho en el sistema de saberes jurídicos", cit.

47 Ferrajoli, Luigi, Los fundamentos de los derechos fundamentales, Madrid, Trotta, 2001, p. 19. 
sión universal de los derechos fundamentales no comprende ni incluye a todos los seres humanos.

Este planteamiento presenta al Estado constitucional de derechos en el marco de la constitucionalización de la sociedad mediante la aplicación directa del texto constitucional, donde cada acto ciudadano debe estar protegido por la Constitución, cuyo despliegue de valores posibilitará los niveles de participación social y de los órganos de poder en la construcción de la justicia, pues como sostiene el mencionado autor, "querer ir más allá del presente Estado de derecho, significa bregar por una dimensión, una forma de actuar y efectividad de la justicia". ${ }^{48}$

En el marco del Estado constitucional de derechos y justicia, es necesario que se impliquen otras dimensiones y valores en normativas y políticas públicas, las que actúan como mecanismos constitucionales para crear justicia, por lo que la democracia inclusiva es una condición para alcanzar la igualdad real.

En tal sentido, la legitimidad democrática está relacionada con el afianzamiento y aseguramiento de los valores y principios constitucionales, el ejercicio de derechos fundamentales y la defensa de la libertad y respeto a la norma y a los órganos judiciales especializados.

Uno de los elementos esenciales de la justicia constitucional tiene relación con la supremacía de la Constitución sobre las normas jurídicas, pero también sobre los actos, planteamiento fundamental para la reconceptualización de las medidas de acción afirmativa, porque están insertas en la dinámica de promoción y consolidación de la democracia, debido al especial interés por los grupos minoritarios y sectores excluidos, ya que constituyen su mecanismo de defensa ético-social, develando su carácter fundamentalmente teleológico.

\section{ACCIÓN AFIRMATIVA EN EL MARCO DE LA DISCRIMINACIÓN ESTRUCTURAL}

Los enfoques, estudios y evidencias acerca de la justicia e igualdad, así como la acción afirmativa, ganan la atención en los foros constitucionales en América Latina, a partir de la década de los años setenta.

48 Ibidem, p. 5. 
Miguel Carbonell, al desarrollar el concepto de "juicios de relevancia", 49 señala que

el principio de igualdad nos indica que si entre dos personas existen diferencias irrelevantes, entonces debemos darle un tratamiento igual; pero también nos exige que si esas personas mantienen diferencias relevantes, entonces el tratamiento que el ordenamiento jurídico les otorgue, también debe ser distinto. ${ }^{50}$

La teoría jurídica contemporánea, para conceptualizar el principio de igualdad, se plantea la disyuntiva entre igualdad y aplicación de la ley, así como la igualdad ante la ley. ${ }^{51}$

El Estado constitucional de derecho provee los instrumentos reglados necesarios en el marco de las funciones que le son inherentes, a efecto de no caer en la contradicción de regular indiferenciadamente a grupos de personas sujetos o en contextos de desigualdad relevante.

El análisis de esta última premisa abarca desde el proceso de diseño de la ley, hasta la elaboración de normativas supletorias que luego serán aplicadas por las autoridades y funcionarios competentes, legislación que deberá contener y manifestar los mandatos de "igualdad sustancial" que exigen la supresión de toda condición que impida la igualdad de oportunidades; estableciendo — de ser el caso- "la implementación de medidas de acción positiva o de discriminación inversa", identificando los grupos y personas tradicionalmente excluidos y en contextos de alta vulnerabilidad para el establecimiento de medidas de "promoción y de especial protección". ${ }^{2}$

Luigi Ferrajoli, al respecto, elabora los conceptos de la igualdad formal y real con miras a destacar las garantías constitucionales en la protección de los derechos ciudadanos, sosteniendo "que la igualdad formal protege-

${ }^{49}$ Concepto que surge de la pregunta que se realiza el autor frente "¿y si nosotros tuviéramos la tarea de legislar y tuviéramos que justificar la elección de ciertos criterios y no de otros bajo los cuales no está permitido distinguir entre las personas?" El jurista establece como requisito el principio de distinción del que deben disponer los ordenamientos jurídicos, sobre la base de criterios que implican y contienen en sí mismo un tratamiento diferenciado entre los grupos y personas sujetos de la acción positiva, cuya ciudadanía participativa es fundamento y base de las garantías constitucionales.

50 Carbonell, Miguel, Neoconstitucionalismo y derechos fundamentales, Quito, Cevallos Editora Jurídica, 2010, p. 189.

51 Ibidem, p. 203.

52 Ibidem, p. 205. 
ría el derecho a la diferencia, es decir, a ser uno mismo y a seguir siendo personas diferentes". 53

La igualdad real, en cambio, protege los "derechos a la compensación de las desigualdades y, por ello, a llegar a ser personas iguales a las demás en las condiciones mínimas de vida y supervivencia". ${ }^{54}$

Los Estados constitucionales de derecho sitúan como eje de las interacciones jurídicas, políticas, sociales, económicas y culturales, a la población que debe contar con instrumentos de aseguramiento, tutela y protección de todas sus garantías constitucionales y, por tanto, de todos sus derechos fundamentales en condiciones de igualdad, equidad y justicia.

\section{MEDIDAS DE ACCIÓN AFIRMATIVA COMO REPARACIÓN}

A LA DESIGUALDAD Y DISCRIMINACIÓN

Ciertamente vivimos una época de crisis civilizatoria, de profundas transformaciones sociales, jurídico-culturales, donde América Latina y algunos países del mundo han optado por ordenamientos constitucionales cuya contemporaneidad se sitúa en un cambio de época y en la centralidad del ciudadano en un Estado de derecho, generando mandatos que obligan a las instituciones y poderes públicos a adoptar medidas, estrategias y acciones positivas para garantizar la igualdad de oportunidades.

Autores como Nagel ${ }^{55}$ y Rodríguez Zepeda, ${ }^{56}$ sostienen que aunque Rawls no abordó el tema de las acciones positivas, éstas se enmarcan en su teoría de la igualdad de oportunidades.

El llamado principio rawlsiano, referido a la igualdad de oportunidades, sostiene que "con objeto de tratar igualmente a todas las personas y de proporcionar una auténtica igualdad de oportunidades, la sociedad tendrá que dar mayor atención a quienes tienen menos dones naturales y a quienes han nacido en las posiciones sociales menos favorables". ${ }^{57}$

53 Ferrajoli, Luigi, Una discusión sobre derecho y democracia, Madrid, Trotta, 2010, p. 47.

54 Idem.

55 Nagel, Thomas, "Rawls and AffirmativeAction", The Journal of Blacks in Higher Education, núm. 39, 2003, pp. 82-84.

56 Rodríguez Zepeda, J., "El igualitarismo radical de John Rawls", Isegoría, núm. 31, 2004, pp. 95-114.

57 Rawls, John, Teoría de la justicia, México, Fondo de Cultura Económica, 2006, p. 103. 
Es claro que las acciones afirmativas aluden a la esencia y efectos de la justicia distributiva y compensatoria, porque existe un evidente proceso de redistribución de los derechos fundamentales que le corresponden a los grupos sometidos a la discriminación y exclusión, así como una acción de restitución y compensación orientada a resarcir los daños causados por la desigualdad.

La acción afirmativa, en el Ecuador, está articulada al objetivo de reducir y remediar las prácticas discriminatorias e inequitativas que afectan la igualdad de oportunidades, la dignidad humana y la libertad, en lo referente a:

- problemas de inequidades e injusticias, a los que han sido sometidos sectores histórica y tradicionalmente excluidos;

- discriminaciones de carácter estructural, sobre todo las que se derivan en ámbitos sociales, políticos, económicos, étnicos, de género, movilidad, cultural y discapacidad;

- situaciones que se relacionan con la gestión de la justicia, sobre todo cuando se constatan ineficacias que afectan a individuos, comunidades, pueblos y nacionalidades; $y$,

- casos de omisión de derechos y reivindicaciones de individuos y colectivos en los ámbitos, económicos, sociales y culturales.

Boaventura de Sousa Santos sostiene que "nosotros tenemos derecho a la igualdad, por cuanto el trato diferente nos inferioriza, nos hace ver menos, pero tenemos derecho a pelear la diferencia cuando la igualdad lo que hace es uniformizarnos, para tratar a todos como idénticos, desconociendo nuestras características propias". ${ }^{58}$

Para Judith Salgado, ${ }^{59}$ la comprensión de la discriminación conduce a entender las relaciones de poder, de donde se generan las llamadas acciones positivas o afirmativas de carácter temporal y que están relacionadas con los conceptos de discriminación positiva o inversa, pues "el Estado constitucional de derechos y de justicia, no puede permanecer neu-

58 Sousa Santos, Boaventura de, "Las tensiones de la modernidad", en Monereo, Manuel y Riera, Miguel (eds.), Porto Alegre. Otro mundo es posible, España, El Viejo Topo, 2001, p. 58.

59 Salgado, Judith, "Discriminación y acción afirmativa", ponencia presentada en el Foro sobre Discriminación Social, Educación y Acciones Afirmativas para el Pueblo Afroecuatoriano, Quito, Universidad Andina Simón Bolívar, 2010. 
tral (permanecer neutral es realmente favorecer a los intereses de los más poderosos)..$^{60}$

En este sentido, la mencionada autora sostiene que las orientaciones de las acciones afirmativas están en relación con "acelerar" la reducción de la desigualdad cuando ésta es estructural, tomando en cuenta el "contexto en el que se aplica", es decir, la igualdad real en situaciones y procesos locales y nacionales como medidas temporales, aunque permanezcan en el tiempo, tienen que ser evaluadas periódicamente para determinar su necesidad y proporcionalidad.

La justificación de la acción afirmativa, según la autora, se sostiene en la llamada igualdad formal, planteamiento que se evidencia en la tutela del Estado, al promover y garantizar la protección ante la ley para evitar los niveles de discriminación, sobre todo las "diferencias que buscan privilegios a unos y a otros desventajas". ${ }^{61}$

Sin embargo, la declaratoria de esta igualdad no es suficiente si la discriminación es una práctica social profunda y existen relaciones "de poder asimétricas y unos tienen el control de recursos, de bienes, de posibilidades de colocar su discurso como verdadero y hay quienes permanecen excluidos totalmente, muy limitados en el acceso". ${ }^{62}$

La autora plantea como alternativa la "igualdad sustancial y el derecho a la diferencia", sobre todo relacionada con los derechos sociales, por lo que bajo el privilegio del derecho a la dignidad humana surge "la idea de la igualdad material, la igualdad sustancial o la igualdad real". ${ }^{63}$

Es necesario destacar que,

cuando hay discriminación hay un trato diferente: si es trato diferente es injusto, arbitrario y busca limitar o anular el ejercicio de un derecho por la pertenencia a un grupo social específico. Por cuestiones éticas, por cuestiones de clases sociales o cuestiones de discapacidades, etcétera. Cuando la diferencia lo que hace es tratar como inferior a alguien, entonces ahí estamos frente a una discriminación. ${ }^{64}$

\footnotetext{
60 Ibidem, p. 4.

61 Ibidem, p. 2.

62 Ibidem, p. 4.

63 Ibidem, p. 3.

64 Ibidem, p. 5.
} 
Esta perspectiva justifica la diferencia en la concepción de la acción afirmativa, porque tratar por igual a personas, comunidades, pueblos y nacionalidades que han sido objeto de desigualdades estructurales e históricas, es perpetuar la discriminación, ya que se estaría promoviendo la persistencia del statu quo de una trayectoria injusta, puesto que se asiste a "un desnivel de oportunidades colocando a todos por igual, a todos como idénticos, cuando en la práctica viven en contextos de desventajas". ${ }^{65}$

\section{CRITERIOS A SER CONSIDERADOS EN LA APLICACIÓN DE MEDIDAS RESTITUTIVAS Y COMPENSATORIAS}

Rosenfeld sostiene, además, que se justifica el trato diferencial cuando los ciudadanos se encuentran en situación de desigualdad, utilizando de parte del Estado y de los operadores de justicia el mecanismo de la acción positiva, que pretende crear medidas equitativas para aquellos ciudadanos que han sido histórica y tradicionalmente excluidos por condición de origen étnico, sexual, social, económico, político, religioso o discapacidad. ${ }^{66}$

La tendencia jurídico-política relacionada con los nuevos debates acerca de principios como la justicia y la igualdad de oportunidades debe orientarse hacia el planteamiento de Barrère, "dirigido a combatir la subordinación o discriminación estructural o de estatus que sufren ciertos grupos", ${ }^{67}$ por lo que es necesario que el estudio se construya en función de los siguientes criterios:

- la cultura jurídica debe superar la orientación de asumir la garantía de los derechos fundamentales, desde premisas como la desigualdad de trato, establecida como criterio primordial en el discurso de la discriminación positiva;

- para las medidas de acción afirmativa es necesario que se plantee la exigibilidad jurídica del ejercicio de los derechos constitucionalizados, toda vez que las problemáticas que se deben abordar no son de carácter individual y coyuntural, sino que son estructurales

65 Idem.

66 Rosenfeld, Michel, Affirmative Action and Justice. A Philosophical and Constitutional Inquiry, New Haven, Yale University Press, 1991 p. 67.

67 Barrere, María de los Ángeles, "Discriminación, derecho...", cit., p. 38. 
y de colectivos sociales, relacionados con la exclusión de género, etnia, discapacidad y condiciones de origen social, económico, político y religioso;

- el abordaje de las tensiones y ambigüedades que produce el principio de igualdad de oportunidades, alrededor de si se trataría de un punto de partida o de sus resultados, incluyen otros criterios como la meritocracia y el desarrollo de capacidades y oportunidades de los grupos excluidos, lo cual demanda en forma urgente, dentro del ordenamiento jurídico vigente, una coherencia sistémica que garantice relaciones sociales igualitarias y el fortalecimiento de la institucionalidad democrática y de justicia;

- son necesarias políticas complementarias que, "impregnadas" de las normas constitucionales, prioricen su carácter de restitutivas - especialmente en el caso educativo - toda vez que el fin del Estado constitucional de derecho y justicia, es la centralidad de los derechos fundamentales y la consecución de una sociedad inclusiva y democrática;

- la superación del discurso hegemónico que pretende asociar la justicia y la igualdad (en las medidas de acción afirmativa), desde la legislación y la jurisprudencia con abordajes reduccionistas que se concentran simplemente en la compensación y el trato preferencial.

- el pensamiento y la doctrina jurídico-política debe irradiarse y enmarcarse en aspectos que integran abordajes causales de carácter social, político, económico y cultural, contenidos en el modelo de sociedad del buen vivir, definido por la Constitución de la República; y,

- profundizar el estudio e intervención que implica la caracterización de la situación de los grupos sociales objetos de la exclusión y la subsunción de la norma, capaz de cumplir a través del despliegue de políticas públicas con los objetivos constitucionales.

\section{CONCLUSIONES}

Es menester profundizar en el desarrollo de los proyectos democráticos y republicanos latinoamericanos el carácter inclusivo en las nuevas na- 
rrativas e imaginarios gubernamentales, como sostiene Williams cuando se refiere a los llamados ideales de la nacionalidad de dichas sociedades que se configuran en contextos en que "las políticas institucionales, las prácticas discursivas y la oferta de derechos sociales fueron excluyentes y/o diferenciados a partir de las líneas trazadas entre clase, raza, género, capacidad o sexualidad". ${ }^{68}$

Por estos motivos las medidas de acción afirmativa deben enmarcarse en los principios que Soasti ${ }^{69}$ sostiene relativos a la ciudadanía efectiva, sobre todo en relación con sociedades - como el caso de la ecuatorianaen las que el nuevo contrato social educativo se establece a partir de la constitucionalización de la sociedad y del ordenamiento jurídico, a saber:

- la igualdad de derechos y oportunidades ante la ley;

- la participación orgánica de los ciudadanos para la conservación de los derechos naturales a la libertad, la propiedad, la seguridad y la resistencia a la opresión y discriminación, y

- la ley como expresión de la voluntad general que, en su elaboración, los ciudadanos tienen derecho a participar con libertad para expresarse.

Desde esta perspectiva, el ciudadano como sujeto de derechos tiene una práctica de participación en el diseño, gestión y evaluación de las medidas de acción afirmativa, que en el marco de la justicia constitucional deben estar orientadas a contribuir en la eliminación de toda forma de discriminación y garantizar la igualdad ante la ley y el goce pleno de derechos, deberes y oportunidades, como dispone el texto constitucional en el título II acerca de los derechos, artículo 11.2, inciso segundo:

Nadie podrá ser discriminado por razones de etnia, lugar de nacimiento, edad, sexo, identidad de género, identidad cultural, estado civil, idioma, religión, ideología, filiación política, pasado judicial, condición socioeconómica, condición migratoria, orientación sexual, estado de salud, portar VIH,

68 Williams, Fiona, "Raza, etnia, género y clase en los Estados de bienestar: un marco para análisis comparativo", Papel Político, núm. 5, 1997, p. 69.

69 Soasti, Guadalupe, "Pedagogía política ilustrada: de vasallo a ciudadano, lo que produjo el conocimiento de los derechos del hombre y el ciudadano", en Soasti, Guadalupe (comp.), Política, participación y ciudadanía en el proceso de independencias en la América andina, Quito, Fundación Konrad Andenauer, 2008, pp. 243-318. 
discapacidad, diferencia física; ni por cualquier otra distinción, personal o colectiva, temporal o permanente, que tenga por objeto o resultado menoscabar o anular el reconocimiento, goce o ejercicio de los derechos. La ley sancionará toda forma de discriminación. ${ }^{70}$

Estas reflexiones son fundamentales para la configuración de nuevas lecturas y análisis jurídicos del paradigma neoconstitucionalista que en el ámbito de la justicia distributiva y constitucional permitirá apalancar la necesidad de fortalecer los valores y principios de construcción de un poder ciudadano generando sus formas de organización, movilización y participación efectiva para la defensa y la aplicación de los derechos fundamentales en beneficio de una ciudadanía diversa y diferenciada, que al decir de Serna "ha sido construida sobre un mundo público que le ha sido extraño o ante un mundo público que difícilmente ha podido ser arbitrado por ciudadanos". ${ }^{71}$

La visión conceptual de la acción afirmativa con enfoques exclusivamente retributivos, basados en procesos de compensación, corrección y reparación debe ser revisada o destinarse exclusivamente a los casos relacionados con las secuelas de discriminación temporal, omisión o ineficacia de la justicia, caso contrario el sentido de circunscribir el ámbito de la restitución a la diada gratificación-consumo basada en la reposición de un bien, para el caso de la educación superior estaría desmarcando la medida política de la justicia distributiva y constitucional, porque promueve la elusión de la responsabilidad del Estado, tal como consta en el texto constitucional al señalar la necesidad de: "Garantizar sin discriminación alguna el efectivo goce de los derechos establecidos en la Constitución y en los instrumentos internacionales, en particular la educación, la salud, la alimentación, la seguridad social y el agua para sus habitantes". ${ }^{72}$

La pertinencia de una nueva conceptualización de la acción afirmativa de carácter integral, se hace urgente para desarrollar nuevas perspectivas y acciones jurídicas y sociales, que propicien la igualdad de oportunidades en contextos más amplios para la reducción de brechas y desigualdades en los ámbitos sociales, económicos, educativos y culturales.

70 Idem.

71 Serna, Adrián, "Prácticas ciudadanas y políticas de la memoria. La ciudadanía, la remembranza y el patrimonio”, en González, J. E. (ed.), Ciudadanía y cultura, Bogotá, Universidad Nacional de Colombia-Tercer Mundo Editores, 2010, pp. 215-240.

72 Ibidem, título 1, artículo 3.1. 
El planteamiento del enfoque de la redistribución incorpora personas, derechos y contextos, cuyas interacciones son fundamentales para la formación universitaria en condiciones de calidad y ejercicio de los derechos, en el marco del reconocimiento de valores y prácticas ético-culturales que configuren, entre otros, los factores de oportunidad de éxito en la formación de tercero y cuarto nivel de educación superior.

En este sentido, es necesario que las medidas de acción afirmativa estén acompañadas de una serie de políticas complementarias y un despliegue normativo destinados no solamente a la restitución de los derechos de individuos y grupos tradicionales históricamente excluidos y en situación de vulnerabilidad, sino también a la generación de oportunidades que eliminen las barreras de acceso, adaptación, permanencia, tránsito y egreso de la educación superior, desplegando acciones que favorezcan su desarrollo presente y el proyecto de futuro ciudadano y de la sociedad.

Katarina Tomasevski, ${ }^{73}$ relatora especial de la UNESCO, sostiene que el verdadero acceso a la educación superior implica políticas de no discriminación, asequibilidad económica y presupuestaria, accesibilidad material y la adaptabilidad y coherencia con el resto de los derechos. ${ }^{74}$

Desde esta perspectiva, eso significa que las normativas referidas a las medidas de acción afirmativa deben estar orientadas jurídica y socialmente a la reducción de las brechas cognitivas y contextuales, producto de las situaciones de pobreza en las que están insertos los grupos tradicionalmente excluidos y a su movilidad social ascendente.

Estos componentes tienen su implicación con una regulación de la acción afirmativa que plantee políticas de:

- optimización de recursos para apoyar las demandas complementarias que exige la formación universitaria, como acceso a tec-

73 Tomasevski, Katarina, El asalto a la educación, Barcelona, Intermon Oxfam Editorial, 2004.

74 Para la autora, las tramas que hay que tomar en cuenta para el caso de: la asequibilidad tienen que ver con el desnivel entre las asignaciones presupuestarias y las obligaciones jurídicas y entre los recursos destinados a la educación y los titulares de derecho a la educación; la accesibilidad relativas a los obstáculos jurídicos, administrativos, económicos, etcétera, para iniciar, permanecer y culminar los estudios, así como a las disparidades y desigualdades por razones de raza, género, etnia, religión, origen, etcétera, en toda la pirámide educativa, y la adaptabilidad en términos de la coherencia reglamentaria entre el derecho a la educación y los demás derechos, así como el planteamiento de una educación para el ejercicio de los derechos específicos. 
nología, libros, transporte, becas, alimentación, entre otros, que favorezca la inclusión educativa;

- adaptación curricular en el ingreso para generar alternativas tutoriales que posibiliten acortar las brechas cognitivas, reconocer las cosmovisiones y prácticas interculturales y enfrentar las condiciones adversas de estudio, sobre todo de grupos étnicos y aquellos que pertenecen a la generación que por primera vez en términos familiares ingresan a la formación de tercer nivel;

- dinamización de los procesos de participación en los procesos educativos, políticos, sociales y culturales, y

- desarrollo de perfiles de competencias y capacidades integrales que fortalezcan el capital cultural y social de individuos y grupos estudiantiles para que respondan de manera autónoma y emancipada a las demandas sociales y del conocimiento.

La complementariedad de las medidas de acción afirmativa con políticas de retención de los grupos tradicionalmente excluidos, son una condición para la democratización y el ejercicio del derecho a la educación, pues la meritocracia como principio esencial educativo, no debe definirse sin tomar en cuenta los contextos de desempeño de dichos estudiantes, que han sido de discriminación y exclusión estructural de origen.

Al explorar estos enfoques paradigmáticos deben ser prolijamente profundizados, porque en materia de educación superior la disputa de poder se realiza en la punga por desmarcar la ciudadanía del código estatal, para pasar a un código societario cuya expresión tiene relación exclusiva con la dinámica de la sociedad civil, excluyendo la responsabilidad jurídica y ética del Estado en materia de garantizar el conocimiento y la educación superior como derechos humanos universales.

Esta perspectiva nos conduce a la contradicción mundo público, relacionado con el Estado versus mundo privado que en los actuales momentos no solo que termina siendo una falacia por los contextos de interacción jurídico, social, político y cultural existentes, sino que además vela por la responsabilidad de las universidades frente a la construcción de lo público del conocimiento y del aprendizaje, en la perspectiva de su redistribución, como única garantía de sostenibilidad de una democracia cognitiva y deliberativa de carácter incluyente.

Hasta el momento, a pesar de las transformaciones que se han operado en la educación superior ecuatoriana con miras a su democratización, lo 
público sigue cargado de concepciones e imaginarios socioculturales con tendencias estratificadoras y jerarquizadoras, aunque se legitimen tres ejes que tienen que ver con la aspiración de socializar la importancia del derecho a la educación y al conocimiento con los "comunes"; la configuración de una inteligencia estratégica colectiva y comunitaria como espacio de inclusión epistemológica, ético y política de la ciudadanía, tal como consta en el Código Ingenios; asimismo, el reconocimiento y la valoración de la diferencia y la diversidad en el marco de la participación igualitaria de los ciudadanos en la construcción de discursos y prácticas plurales y afiliadas con el interés general.

Las medidas de acción afirmativa constituyen una política de sostenibilidad futura de democracias altamente participativas, incluyentes, diversas y justas, que desde el enfoque de la redistribución aportaría al quiebre de una educación superior estratificada, que profundiza las jerarquías sociales, dando paso a procesos de movilidad social ascendente de los grupos tradicionalmente excluidos a partir del fortalecimiento de su capital cultural y social.

\section{BiBLIOGRAFÍA}

Alexy, Robert, Tres escritos sobre los derechos fundamentales y la teoría de los principios, Bogotá, Universidad Externado de Colombia, 2003.

ARISTóteles, Ética nicomaquea. Ética eudemia, Madrid, Gredos, 2003.

Asti, José et al., Discriminación positiva: un acercamiento sobre la inclusión de la mujer en la política peruana a propósito de las cuotas de género, s. p. i., 2014,

BARrere, María de los Ángeles, "Discriminación, derecho antidiscriminatorio y acción positiva vs. Igualdad de oportunidades", Revista Vasca de Administración Pública, núm. 60, 2001.

Bossini, Francisco R. y GLEeson, Mary, Diccionario bilingüe de terminología jurídica, Madrid, McGraw-Hill, 1998.

CARbonell, Miguel y García, Leonardo B., El canon neoconstitucional, Colombia, Universidad Externado, 2010.

CArbonell, Miguel, Neoconstitucionalismo y derechos fundamentales, Quito, Cevallos Editora Jurídica, 2010. 
Cohen, Carl y Sterba, James, Affirmative Action and Racial Preferences: A Debate, Nueva York, Oxford University Press, 2003.

Comanducci, Paolo, "Formas de (neo)constitucionalismo", Isonomía, México, Instituto Tecnológico Autónomo de México, núm. 16, 2002.

Collin, P. H., Dictionary of Law, Bloomsbury Publishing Plc, 2004.

DíAz Romero, Pamela et al., Caminos para la inclusión en la educación superior, Perú, Fundación Equitas-Organización de Estados Iberoamericanos, 2006.

DuARTE, Bernardo, "El acceso a la educación superior: sistemas de admisión a las universidades nacionales de Argentina", ponencia presentada en el Primer Congreso Nacional de Estudios Comparados en Educación, Buenos Aires, 2005.

Dworkin, Ronald, A Matter of Principle, Oxford, Clarendon Press, 1986.

FERrajoli, Luigi, Los fundamentos de los derechos fundamentales, Madrid, Trotta, 2001.

Ferrajoli, Luigi, "La teoría del derecho en el sistema de saberes jurídicos", en FerRajoli, Luigi et al., La teoría del derecho en el paradigma constitucional, Madrid, Fundación Coloquio Jurídico Europeo, 2008.

Ferrajoli, Luigi, Una discusión sobre derecho y democracia, Madrid, Trotta, 2010.

Fraser, Nancy, Unruly Practices: Power, Discourse and Gender in Contemporary Social Theory, Oxford, 1989.

FULLINWIDER, Robert, La controversia de la discriminación inversa, Nueva Jersey, Rowman and Littlefield, 1980.

Greenwalt, Kent, La discriminación inversa, Nueva York, Alfred A. Knopf,1983.

Guastini, Riccardo, La “constitucionalización” del ordenamiento jurídico: el caso italiano, Madrid, Trotta, 2005.

HobBes, Thomas, Leviatán, Oxford, Oxford Clasics, 1996.

Honneth, Alex, "Integrity and Disrespect: Principles of a Conception of Morality Based on the Theory of Recognition", Political Theory, vol. 20, núm. 2, mayo de 1992.

Kant, Inmanuel, Crítica de la razón pura, Madrid, Taurus, 2005.

Locke, John, Dos ensayos sobre el gobierno civil, México, Porrúa, 2003. 
NAgEL, Thomas, "Rawls and AffirmativeAction", The Journal of Blacks in Higher Education, núm. 39, 2003.

Nussbaum, Martha, Las fronteras de la justicia, Madrid, Paidós, 2007.

Platón, La República, Madrid, Instituto de Estudios Políticos, 1949.

RAMírez, René, Universidad urgente para una sociedad emancipada, Ecuador, Senescyt-IESALC, 2016.

RAWLS, John, La justicia como equidad. Una reformulación, Madrid, Paidós Ibérica, 2001.

Rawls, John, Teoría de la justicia, México, Fondo de Cultura Económica, 2006.

RodríGUez ZEPEDA, J., "El igualitarismo radical de John Rawls", Isegoría, núm. 31, 2004.

Rosenfeld, Michel, Affirmative Action and Justice. A Philosophical and Constitutional Inquiry, New Haven, Yale University Press, 1991.

Rousseau, Jean Jacques, Contrato social, París, Gallimard Pléiade, 1964. RuIz, Alfonso, "La discriminación inversa y el caso Kalanke", Doxa, Cuadernos de Filosofía del Derecho, España, Universidad de Alicante, núm. 19, 1996.

SAlgado, Judith, "Discriminación y acción afirmativa", ponencia presentada en el Foro sobre Discriminación Social, Educación y Acciones Afirmativas para el Pueblo Afroecuatoriano, Quito, Universidad Andina Simón Bolívar, 2010.

Secretaría Nacional de Educación Superior, Ciencia, tecnología e innovación. Logros y avances del sistema de educación superior ecuatoriano, Quito, Senescyt, 2014.

SEn, Amartya, La idea de la justicia, México, Taurus, 2010.

SAn Miguel, Johannes y Granados, Víctor, “¡Del romanticismo al realismo mágico! Contenido y principales postulados de la tesis neoconstitucional europea y latinoamericana", Cadernos de Dereito Actual, núm. 4, 2016, disponible en: http://www.cadernosdedereitoactual. es/ojs/index.php/cadernos/article/view/95).

SoAsti, Guadalupe, "Pedagogía política ilustrada: de vasallo a ciudadano, lo que produjo el conocimiento de los derechos del hombre y el ciudadano", en Soasti, Guadalupe (comp.), Política, participación y ciuda- 
Esta revista forma parte del acervo de la Biblioteca Jurídica Virtual del Instituto de Investigaciones Jurídicas de la UNAM

danía en el proceso de independencias en la América andina, Quito, Fundación Konrad Andenauer, 2008.

Sousa SAntos, Boaventura de, "Las tensiones de la modernidad", en Monereo, Manuel y Riera, Miguel (eds.), Porto Alegre. Otro mundo es posible, España, El Viejo Topo, 2001.

TIERnEY, William, "The Parament of Affirmative Action: Equity and Excellent in the Academy", Review of Educational Research Summer, vol. 67, núm. 2, 1997.

Williams, Fiona, "Raza, etnia, género y clase en los Estados de bienestar: un marco para análisis comparativo", Papel Político, núm. 5, 1997.

Zagrebelsky, Gustavo, El derecho dúctil, Madrid, Trotta, 1997.

Fecha de recepción: 25 de abril de 2017.

Fecha de dictamen: 15 de diciembre de 2017. 